\title{
Oxidized low density lipoprotein facilitates tumor necrosis factor- $\alpha$ mediated chondrocyte death via autophagy pathway
}

\author{
PENGCHENG SHEN ${ }^{1,2}$, YU ZHU ${ }^{3}$, LIFAN ZHU ${ }^{2}$, FENGBIAO WENG ${ }^{2},{\text { XIAOLIN } \mathrm{LI}^{4} \text { and YAOZENG XU }}^{1}$ \\ ${ }^{1}$ Department of Orthopaedics, The First Affiliated Hospital of Soochow University, Suzhou, Jiangsu 215006; \\ ${ }^{2}$ Department of Orthopaedics, The First People's Hospital of Wujiang District, Suzhou, Jiangsu 215200; ${ }^{3}$ Department of \\ Orthopaedics, Suzhou Hospital of Traditional Chinese Medicine, Suzhou, Jiangsu 215100; ${ }^{4}$ Department of Orthopaedics, \\ Shanghai Sixth People's Hospital Affiliated to Shanghai Jiaotong University, Shanghai 200233, P.R. China
}

Received June 1, 2017; Accepted October 2, 2017

DOI: $10.3892 / \mathrm{mmr} .2017 .7786$

\begin{abstract}
We aimed to investigate the role of oxidized low density lipoprotein (ox-LDL) in tumor necrosis factor- $\alpha$ (TNF- $\alpha$ ) mediated chondrocyte death and explore the mechanisms. Ten osteoarthritis (OA) and normal control cartilage tissue and synovial fluid (SF) samples were collected, and the expression of lectin-like ox-LDL receptor-1 (LOX-1) and ox-LDL level was examined by real time quantitative PCR and enzyme-linked immunosorbent assay (ELISA). An in vitro chondrocyte model was established by the introduction of TNF- $\alpha$ and ox-LDL, cell death was analyzed by trypan blue assay and the mechanisms were explored based on the apoptosis related pathway and autophagy pathway. Significantly increased ox-LDL level $(70.30 \pm 17.83$ vs. $37.22 \pm 19.97, \mathrm{P}<0.05)$ in SF sample and LOX-1 expression level $(0.51 \pm 0.10$ vs. $0.32 \pm 0.04, \mathrm{P}<0.05)$ in cartilage tissue was found in OA patients compared to those corresponding samples from control subjects. Ox-LDL could facilitate TNF- $\alpha$ mediated chondrocyte death and this effect could be blocked by LOX-1 antibody neutralization. Autophagy inhibition by 3-MA and Atg-5 siRNA could reverse the cell death effect mediated by TNF- $\alpha$ and ox-LDL co-treatment on chondrocytes. Oxidized low density lipoprotein facilitates tumor necrosis factor- $\alpha$ mediated chondrocyte death via its interaction with LOX-1, and autophagy is involved in the mechanisms.
\end{abstract}

\section{Introduction}

Osteoarthritis (OA) represents the most prevalent type of joint disease especially in the elderly and it is estimated that about 3 million newly diagnosed OA could be presented

Corresponding to: Dr Yaozeng Xu, Department of Orthopaedics, The First Affiliated Hospital of Soochow University, 188 Shizi Street, Suzhou, Jiangsu 215006, P.R. China

E-mail: xuyaozeng@suda.edu.cn; m13862546422@163.com

Key words: oxidized low density lipoprotein, lectin-like ox-low density lipoprotein receptor-1, chondrocyte, tumor necrosis factor- $\alpha$, autophagy each year $(1,2)$. In current clinical practice, joint replacement remains the preferred treatment method for patients with advanced OA (3). However, due to the lacking of knowledge about the disease pathophysiology, only a few effective disease-modifying therapies has been proposed for OA treatment. Therefore, investigate the disease mechanism will give insights for the treatment.

OA is characterized by extracellular matrix destruction and chondrocyte function loss (apoptosis) and multiple risk factors could result in this phenomenon, including mechanical injury, aging and inflammation (4). Enhanced chondrocyte apoptosis is considered as the sign of cartilage joint degeneration in OA (5). Studies have shown that a variety of stimuli including tumor necrosis factor- $\alpha$ (TNF- $\alpha)(6)$, TNF-related apoptosis-inducing ligand (TRAIL) (7) and nitric oxide (8) were involved in the chondrocytes apoptosis process. Recent epidemiology and experimental studies have shown that lipid peroxidation was involved in the pathogenesis of OA $(9,10)$. Associations were found between hypercholesterolemia or hypertension and OA $(9,10)$. Joint manifestation are frequently presented in patients with familial hypercholesterolemia, which is characterized by a decreased removal of low-density lipoprotein (LDL), and treatment with a lipid-lowering diet attenuates the incidence of joint involvement (11). However, the few studies has explored the detailed events involved in these events.

Here, we aimed to investigate the role of oxidized low density lipoprotein (ox-LDL) in TNF- $\alpha$ mediated chondrocyte death and explore the mechanisms. Based on our patient data and cell model experiment data, we demonstrated that ox-LDL could enhance TNF- $\alpha$ mediated chondrocyte death via autophagy related pathway.

\section{Materials and methods}

$O A$ cartilage and SF samples. OA $(\mathrm{n}=40)$ cartilage and synovial fluid (SF) samples were collected at the time of total knee arthroplasty at Shanghai Sixth People's Hospital, Shanghai, China. Normal cartilage and SF from patients $(n=40)$ with no history of OA was obtained from Shanghai Sixth People's Hospital. Cartilage and SF samples were stored in $-80^{\circ} \mathrm{C}$ before further processing. The demographic data of 
these patients, including age, gender, body mass index (BMI), disease duration, the total Western Ontario and McMasters University Osteoarthritis Index (WOMAC) score, ox-LDL level and Lox-1 level, were also collected and listed in Table I. Among these indexed, the total WOMAC score includes WOMAC pain score and WOMAC function score, and functional disability and pain were assessed by self-reported questionnaires according to previous publications $(12,13)$. All research involving human participants was approved by the Institutional Review Board of Shanghai Jiaotong University School of Medicine, Shanghai, China. Written informed consent was collected from all the participants.

Enzyme-linked immunosorbent assay. SF samples were examined with enzyme-linked immunosorbent assay (ELISA) kit from Cell Biolabs Inc., (San Diego, CA, USA) and the absorbance value was measured at $450 \mathrm{~nm}$ to concentration measurement according to the manufacturer's instructions.

Quantitative real-time reverse transcription-polymerase chain reaction ( $q R T-P C R)$ assay. Total cellular RNA was extracted from of cartilage tissue with TRIzol reagent (Invitrogen Life Technologies, Carlsbad, CA, USA). RT-PCR was carried out using a One Step SYBR ${ }^{\circledR}$ PrimeScript $^{\mathrm{TM}}$ RT-PCR kit (Takara Bio, Dalian, China) and an iQ5 Real-time PCR Detection system (Bio-Rad, Hercules, CA, USA). Expression of the glyceraldehyde 3-phosphate dehydrogenase (GAPDH) gene was assayed simultaneously with samples as an internal control. Relative gene expression was determined by the $2^{-\Delta \Delta C T}$ method (14). Oligonucleotide primers specific for LOX-1 and GAPDH are listed in Table II.

Cell culture and treatment. Human articular chondrocyte culture was purchased from cell culture collection of Fudan University, Shanghai, China, and cultured according to the manufacturer's instruction. Cell were plated at a density of $1 \times 10^{4} / \mathrm{cm}^{2}$ in a human chondrocyte medium containing chondrocyte growth supplement and penicillin/streptomycin (ScienCell, Carlsbad, CA, USA) and incubated at $37^{\circ} \mathrm{C}$ in a humidified $5 \% \mathrm{CO}_{2}$ incubator. In the setting of LOX-1 neutralization, chondrocytes at $70-80 \%$ confluency were pre-incubated with or without anti-LOX-1 antibody $(10 \mu \mathrm{g} / \mathrm{ml})$ before processing for vehicle control or TNF- $\alpha(50 \mathrm{ng} / \mathrm{ml})$ or ox-LDL (20 $\mu \mathrm{g} / \mathrm{ml}$, Yiyuan biotech, Guangzhou, China) or TNF- $\alpha(50 \mathrm{ng} / \mathrm{ml})$ and ox-LDL $(20 \mu \mathrm{g} / \mathrm{ml})$ co-treatment for 24-48 h. In the experiment of autophagy inhibition, chondrocytes at $70-80 \%$ confluency were pre-treated with or without 3-MA (10 $\mathrm{mM})$ for $24 \mathrm{~h}$ before processing for vehicle control or TNF- $\alpha(50 \mathrm{ng} / \mathrm{ml})$ and ox-LDL $(20 \mu \mathrm{g} / \mathrm{ml})$ co-treatment for $24 \mathrm{~h}$.

Lenti-virus mediated autophagy protein 5 (ATG5) knockdown. ATG5 siRNA lentivirus and control lentivirus were obtained from Shanghai Hanbio Co. Ltd., Shanghai, China. Chondrocytes cultured in a 6 well plate at $50 \%$ confluence were infected with $50 \mu \mathrm{l}$ ATG5 siRNA and control lentivirus in $3 \mathrm{ml}$ serum free human chondrocyte medium containing $8 \mu \mathrm{g} / \mathrm{ml}$ puromycin for $24 \mathrm{~h}$. Medium change was performed after $24 \mathrm{~h}$ and the efficacy of ATG-5 knockdown was verified by western blotting. Chondrocytes were collected at $48 \mathrm{~h}$ after lentivirus infection, followed by TNF- $\alpha(50 \mathrm{ng} / \mathrm{ml})$ and ox-LDL $(20 \mu \mathrm{g} / \mathrm{ml})$ co-treatment for $24 \mathrm{~h}$.

Cell viability. Cell viability was determined by trypan blue exclusion assay.

Immunofluorescence. Cells were collected onto a clean glass slide by using centrifugation at $1,000 \mathrm{rpm}$ for $5 \mathrm{~min}$. The slide was then incubated with LC3 primary antibody for $1 \mathrm{~h}$ at $37^{\circ} \mathrm{C}$, washed 3 times with PBS, incubated with FITC-conjugated secondary antibody for $1 \mathrm{~h}$ at room temperature and finally dropped with DAPI containing anti-quench reagents. Fluorescence images were observed and analyzed using Zeiss LSM 510 laser-scanning confocal microscope (Goettingen, Germany).

DNA fragmentation assay. After serum-starvation for $12-24 \mathrm{~h}$, the medium was changed to serum-free medium containing Ox-LDL (20 $\mu \mathrm{g} / \mathrm{ml})$ or vehicle control for 24-48 h. Cells were washed with ice-cold PBS and lysed in a buffer containing $10 \mathrm{mM}$ Tris- $\mathrm{HCl}, \mathrm{pH} 7.4,150 \mathrm{mM} \mathrm{NaCl}, 0.3 \% \mathrm{SDS}$ and $20 \mathrm{mM}$ EDTA at $4^{\circ} \mathrm{C}$ for $30 \mathrm{~min}$. After incubation with RNase A $(20 \mu \mathrm{g} / \mathrm{ml})$ and proteinase $\mathrm{K}(0.4 \mathrm{mg} / \mathrm{ml})$, DNA was extracted with phenol-chloroform-isoamyl alcohol (25:24:1), dissolved in $30 \mu 1$ Tris-EDTA buffer, and then subjected to $3 \%$ agarose gel electrophoresis. Fragmented DNA was visualized with the SYBR green I DNA staining system.

Western blot analysis. Cells treated according to abovementioned procedure were lysed in RIPA buffer, followed by high speed centrifugation and protein quantification using a bicinchoninic acid assay. Cellular proteins were separated by sodium dodecyl sulfate-polyacrylamide gel electrophoresis and transferred to polyvinylidenedifluoride membranes. After blocking, the membranes were incubated with primary monoclonal antibodies against LC3, Caspase- 8 and Caspase- 3 (Cell Signaling Technology, Cambridge, MA, USA). $\beta$-actin (Santa Cruz Biotechnology, Santa Cruz, CA, USA) was used as the loading control. Horseradish peroxidase-conjugated secondary antibodies were applied to detect labeled proteins. Protein bands were developed with SuperSignal Ultra Chemiluminescent Substrate (Pierce, Rockford, IL, USA) on X-ray films (Kodak, Tokyo, Japan).

Statistical analysis. Statistical analysis was carried out using SPSS v18 (SPSS, Chicago, IL, USA). Data were reported as means \pm standard deviation (SD). Student's t-test or one-way analysis of variance was used to determine the significance of difference between groups. $\mathrm{P}<0.05$ was considered to indicate a statistically significant difference.

\section{Results}

Increased level of ox-LDL and Lox-1 in OA patients. In order to clarify the possible role of ox-LDL and Lox-1 during the presence of osteoarthritis, we firstly collected SF and cartilage samples from 40 OA patients and 40 normal control subjects (please see Table II about the demographic data of these subjects) and determined the ox-LDL level in SF and Lox-1 expression in cartilage tissues by ELISA 
Table I. Demographic data of the osteoarthritis patients.

\begin{tabular}{lcc}
\hline & $\begin{array}{c}\text { Healthy controls } \\
(\mathrm{n}=40)\end{array}$ & $\begin{array}{c}\text { Patient } \\
(\mathrm{n}=40)\end{array}$ \\
\hline Age & $47.7 \pm 10.4$ & $57.4 \pm 10.2$ \\
Sex $(\mathrm{female}, \%)$ & $22(55 \%)$ & $21(52.5 \%)$ \\
BMI $\left(\mathrm{kg} / \mathrm{m}^{2}\right)$ & $27.5 \pm 4.5$ & $26.2 \pm 3.9$ \\
Disease duration & - & $52.2 \pm 38.1$ \\
Total WOMAC score & - & $73.0 \pm 19.9$ \\
LOX-1 level & $0.33 \pm 0.04$ & $0.49 \pm 0.11$ \\
Ox-LDL level $(\mathrm{mU} / \mathrm{ml})$ & $34.5 \pm 15.7$ & $64.8 \pm 18.3$ \\
\hline
\end{tabular}

Ox-LDL, oxidized low density lipoprotein; LOX-1, lectin-like ox-low density lipoprotein receptor-1; BMI, mody mass index; WOMAC, Western Ontario and McMasters University Osteoarthritis Index.

and qRT-PCR, respectively. The results showed that significantly increased ox-LDL level $[(64.8 \pm 18.3) \mathrm{mU} / \mathrm{ml} \mathrm{vs}$. (34.5 \pm 15.7$) \mathrm{mU} / \mathrm{ml}, \mathrm{P}<0.05$ ] (Fig. 1A) and Lox-1 expression $(0.49 \pm 0.11$ vs. $0.33 \pm 0.04, \mathrm{P}<0.05)$ could be found in $\mathrm{OA}$ patients compared to normal controls (Fig. 1B). Moreover, we also found that correlations could be found between the ox-LDL ( $\mathrm{r}=0.786, \mathrm{P}<0.01)$ (Fig. 1C) or Lox-1 $(\mathrm{r}=0.805$, $\mathrm{P}<0.01$ ) (Fig. 1D) and the total WOMAC score, which is a common disease severity indexes used in OA. In addition, the association between ox-LDL and LOX-1 was also observed according to the correlation analyses $(r=0.635$, $\mathrm{P}<0.05$ ) (Fig. 1E). These results suggested that increased level of ox-LDL and Lox-1 was presented in OA patients and according to the results from correlation analyses, ox-LDL and Lox-1 may be involved in the pathogenesis of OA.

Facilitation of TNF- $\alpha$-mediated chondrocyte death by $o x-L D L$. According to the previous description (15), low-grade inflammation with increased expression of proinflammatory cytokines (eg. TNF- $\alpha$ ) in articular cartilage and synovium result in chondrocyte death and contribute to disease progression of OA. Since the increased ox-LDL level and Lox-1 expression was found in OA patients and they were considered to be involved in the disease process of OA, we further established an in vitro TNF- $\alpha$ mediate chondrocyte inflammation model to clarify the role of ox-LDL and LOX-1 during OA process. As shown in Fig. 2A, TNF- $\alpha$ and ox-LDL alone did not affect the cell death obviously compared to the control (TNF- $\alpha$ vs. ox-LDL vs. Control: $4.65 \pm 2.21 \%$ vs. $6.86 \pm 4.65 \%$ vs. $3.60 \pm 1.04 \%, \mathrm{P}>0.05)$, however, combine use TNF- $\alpha$ and ox-LDL could result in significantly increased chondrocyte death and these effects could be reversed by Lox-1 monoclonal antibody (TNF+oxLDL vs. control: $66.90 \pm 6.98 \%$ vs. $3.60 \pm 1.04 \%$; TNF+oxLDL vs. TNF+oxLDL+Lox-1 Ab: $66.90 \pm 6.98 \%$ vs. $11.40 \pm 1.50 \%$, $\mathrm{P}>0.05)$. In order to further confirmed the cell phenomenon during the TNF- $\alpha$ and ox-LDL combined treatment, we employed DNA fragmentation assay and flow cytometry assay to verification. Our results demonstrated obvious DNA fragmentation phenotype could be found during the combine use TNF- $\alpha$ and ox-LDL, but not in the condition
Table II. Primer sequences.

\begin{tabular}{lll}
\hline $\begin{array}{l}\text { Gene } \\
\text { name }\end{array}$ & \multicolumn{1}{c}{$\begin{array}{c}\text { Forward } \\
\text { primer }\left(5^{\prime}-3^{\prime}\right)\end{array}$} & \multicolumn{1}{c}{$\begin{array}{c}\text { Reverse } \\
\text { primer }\left(5^{\prime}-3^{\prime}\right)\end{array}$} \\
\hline LOX-1 & $\begin{array}{l}\text { TTACTCTCCATG } \\
\text { GTGGTGCC }\end{array}$ & $\begin{array}{l}\text { AGCTTCTTCTGC } \\
\text { TTGTTGCC }\end{array}$ \\
GAPDH & CAAAGCCAGAG & GATGGTCTTGGT \\
& TCCTTCAGA & CCTTAGCC \\
\hline
\end{tabular}

LOX-1, lectin-like ox-low density lipoprotein receptor-1.

of TNF- $\alpha$ and ox-LDL alone, and DNA fragmentation could be abolished by Lox-1 antibody (Fig. 2B); moreover, the flow cytometry results of cell apoptosis showed similar trend and the cell apoptosis rate under control, TNF- $\alpha$, ox-LDL, TNF+oxLDL and TNF+oxLDL+Lox-1 Ab was 3.0, 4.0, 6.4, 62.7 and $13.7 \%$, respectively (Fig. 2C). In addition, we also employed western-blotting to examine the apoptosis initiate caspase (caspase-8) and executioner caspase (caspase-3) and the results showed that increased level of cleaved caspase- 8 and caspase- 3 were found in the setting of TNF- $\alpha$ and ox-LDL combination, which could be abolished by adding in Lox-1 antibody (Fig. 2D). These results indicated that ox-LDL could facilitate the TNF- $\alpha$ effects on chondrocyte death by increasing cell apoptosis. Autophagy is involved in the cell death process mediated by TNF- $\alpha$ and ox-LDL.

According to previous description (16), both apoptotic as well as non-apoptotic mechanisms were involved in the cell death affected by OA and autophagy related cell death was considered as one of novel mechanism involved in the chondrocyte death. We therefore examined the autophagy classical marker LC3 by western-blotting and immunofluorescence. As shown in Fig. 3A, we found that increased LC3-II, which is an indicator of autophagy activation, was found after TNF- $\alpha$ and ox-LDL combination treatment, and this process could be blocked by Lox-1 antibody neutralization. The immunofluorescence results in Fig. 3B also confirmed the effects of TNF- $\alpha$ and ox-LDL combination on autophagy activation by LC3 green fluorescence and Lox-1 antibody treatment could inhibit this process. These results indicated autophagy is involved in the cell death process mediated by TNF- $\alpha$ and ox-LDL.

Autophagy inhibition reverse the cell death process mediated by $T N F-\alpha$ and $o x-L D L$. Since the above results suggested the involvement and enhancement of autophagy process in the cell death process mediated by TNF- $\alpha$ and ox-LDL, we here further determined the cell death by induction of autophagy inhibition by classical autophagy inhibitor 3-MA and ATG5 siRNA. According to the results, both 3-MA and ATG5 siRNA treatment could result in the decreased level of LC3II, which was verified by western-blotting (Fig. 4A for 3-MA; Fig. 4E for ATG5 siRNA) and immunofluorescence (Fig. 4B for 3-MA; Fig. 4F for ATG5 siRNA). We further employed the cell viability counting to verify the cell death phenotype, both 3-MA and ATG5 siRNA treatment could result in decreased cell death as shown in Fig. 4C and G, respectively. In addition, 
A

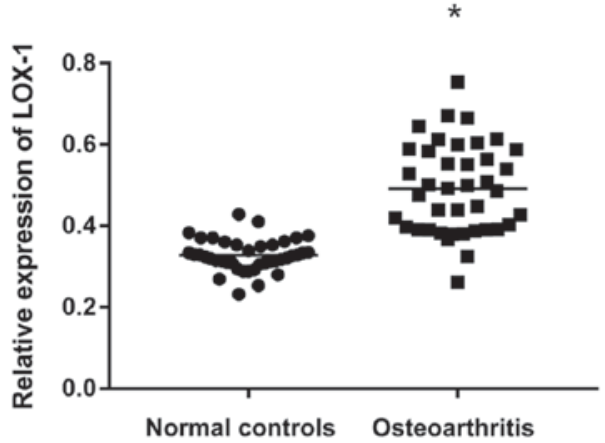

C

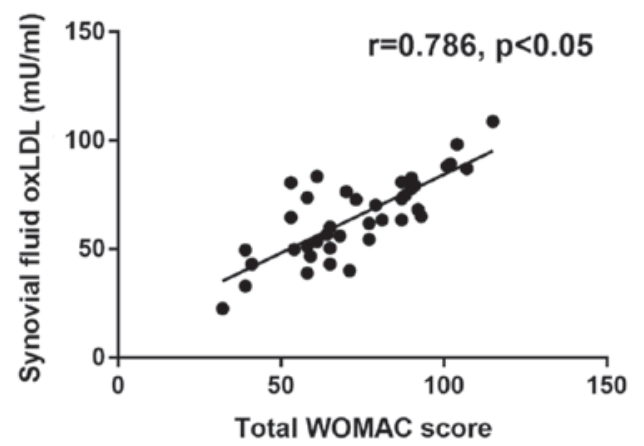

E

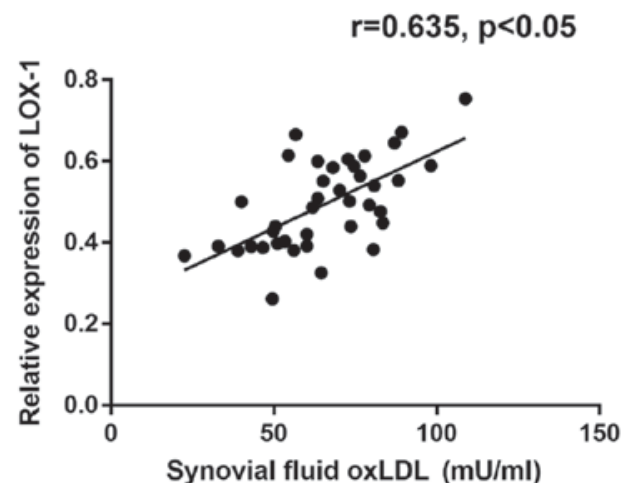

B

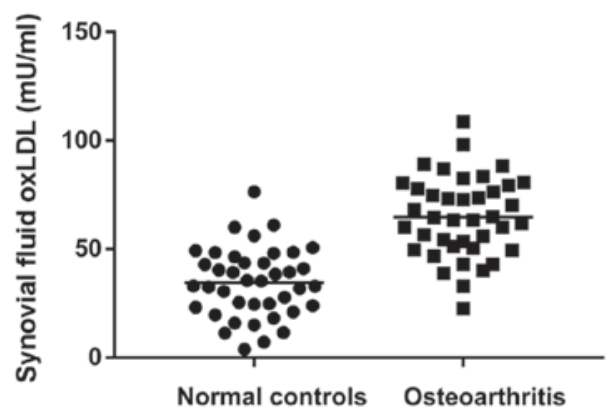

D $r=0.805, p<0.05$

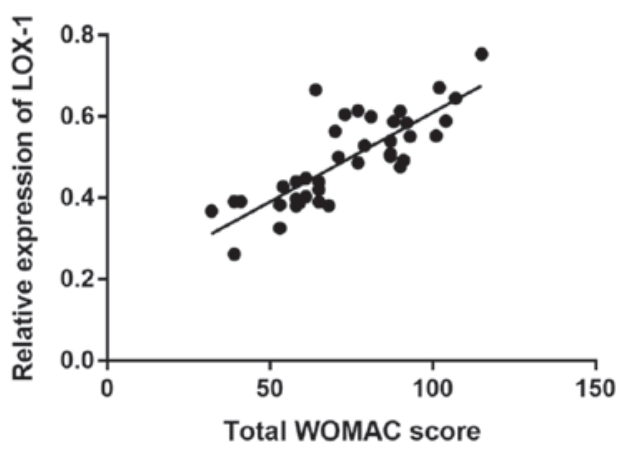

Figure 1. Increased level of ox-LDL and Lox-1 in patients with osteoarthritis are correlated with the total WOMAC score. A total of 40 cases of osteoarthritis $(n=40)$ and 40 cases of normal controls $(n=40)$ were included. (A) Relative Lox-1 expression and (B) levels of synovial fluid ox-LDL was determined by ELISA and quantitative real time polymerase chain reaction. Moreover, correlation analyses were performed between (C) ox-LDL level or (D) Lox-1 level and the total WOMAC score and (E) between ox-LDL level or Lox-1 level. * $\mathrm{P}<0.05$ compared to normal control. WOMAC, Western Ontario and McMasters University Osteoarthritis Index; ox-LDL, oxidized low density lipoprotein; Lox-1, lectin-like ox-LDL receptor-1.

the western-blotting analysis of caspase- 8 and caspase-3 also verified that both 3-MA and ATG5 siRNA treatment could decreased the level of cleaved caspase-8 and capase-3 (Fig. 4D for 3-MA; Fig. 4H for ATG5 siRNA). Taken together, by using small molecule inhibitor 3-MA and gene manipulating ATG5 knockdown, we confirmed the autophagy inhibition could reverse the cell death process mediated by TNF- $\alpha$ and ox-LDL.

\section{Discussion}

In present study, we first found that significantly increased ox-LDL level in SF sample and LOX-1 expression level in cartilage tissue was found in OA patients compared to those corresponding samples from control subjects. Based on this phenotype, we further explored the effect of ox-LDL on TNF- $\alpha$ mediated chondrocyte death, and results showed that ox-LDL could facilitate TNF- $\alpha$ mediated chondrocyte death and this effect could be blocked by LOX-1 antibody neutralization. Moreover, we also found that autophagy inhibition by 3-MA and Atg-5 siRNA could reverse the cell death effect mediated by TNF- $\alpha$ and ox-LDL co-treatment on chondrocytes. Therefore, we concluded that ox-LDL facilitates tumor necrosis factor- $\alpha$ mediated chondrocyte death via its interaction with LOX-1 and autophagy is involved as the mechanisms. To the best of our knowledge, this the first report to link ox-LDL, chondrocyte death and autophagy.

According to recent studies, peroxidation of serum LDL was observed during the inflammation and infection process (17). During the osteoarthritis or rheumatoid arthritis, accelerated vascular porosity could be initiated by inflammation, thereby resulting in invasion of various inflammatory cells and permeation of the biological activators, such as 
A

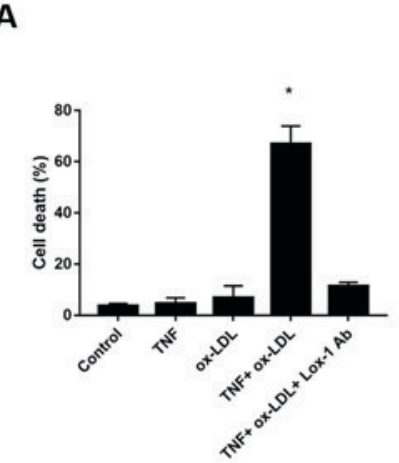

B

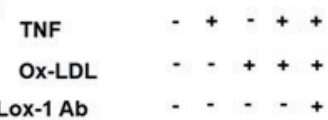

Lox-1 Ab

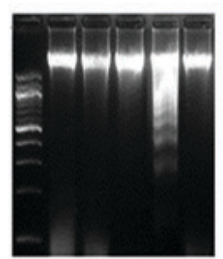

D

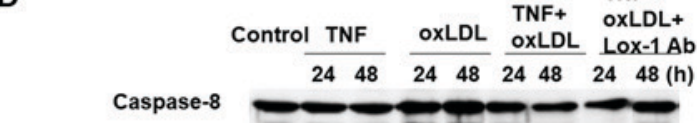

Cleaved caspase-8

Caspase-3

Cleaved caspase-3

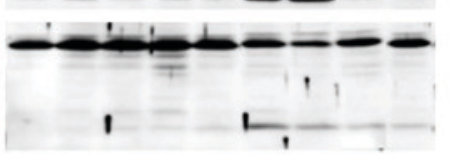

$\beta$-actin
C

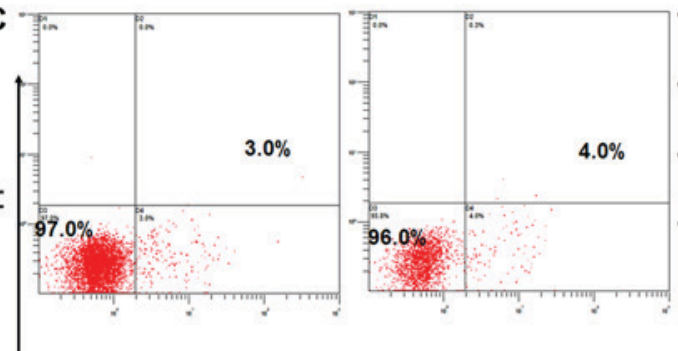

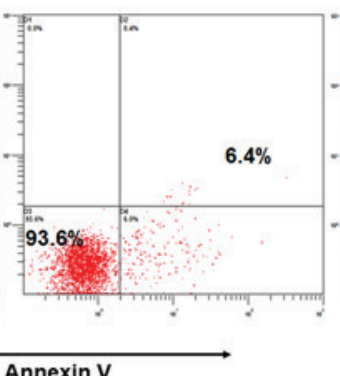

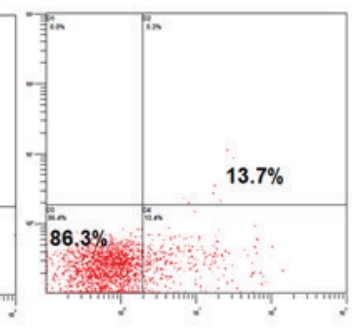

Figure 2. Facilitation of TNF- $\alpha$-mediated chondrocyte death by oxidized low density lipoprotein (ox-LDL). After 30 min preincubation with or without antiLOX-1 antibody $(10 \mu \mathrm{g} / \mathrm{ml})$, Chondrocytes were co-treated with TNF- $\alpha(50 \mathrm{ng} / \mathrm{ml})$ and ox-LDL $(20 \mu \mathrm{g} / \mathrm{ml})$, and harvested at 24 or $48 \mathrm{~h}$ for (A) cell death ,(B) DNA fragmentation assay, (C) Flow cytometry analysis of the chrondrocyte apoptosis by Annexin V/PI staining and (D) western blot analysis of apoptosis related proteins. (A , B and C) Ox-LDL co-treatment could facilitate TNF- $\alpha$-mediated chondrocyte death and this process could be blocked by Lox-1 monoclonal antibody pretreatment. (D) Western-blot analysis revealed that increased level of cleaved caspase- 8 and caspase- 3 in TNF- $\alpha$ and ox-LDL co-treated chondrocytes, and that this effect could be blocked by Lox- 1 antibody pretreatment. $* \mathrm{P}<0.05$ compared to control. ox-LDL, oxidized low density lipoprotein; Lox-1, lectin-like ox-LDL receptor-1; TNF- $\alpha$, tumor necrosis factor $\alpha$; Ab, antibody; PI, propidium iodide.

A

\section{B}

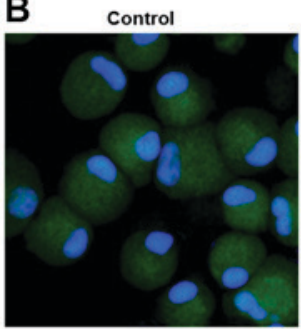

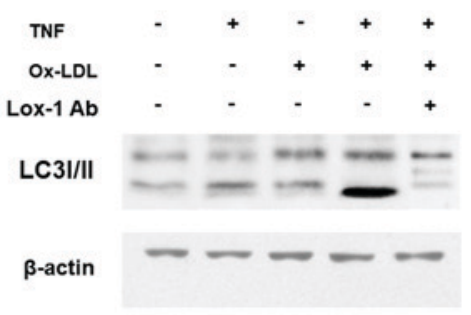

TNF

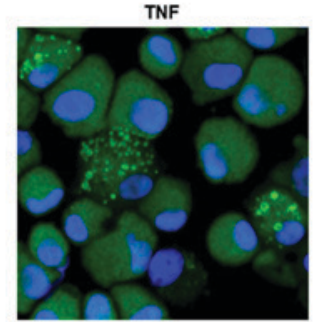

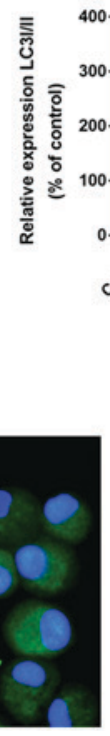

oxLDL

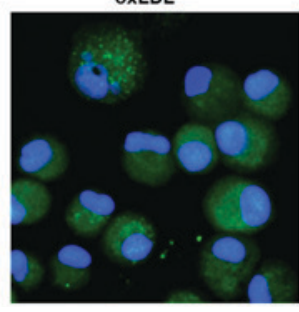

TNF+oxLDL

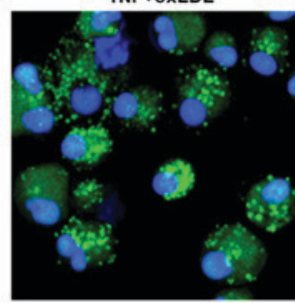

- LC31

[EC LCII

Figure 3. Autophagy is involved in the cell death process mediated by TNF- $\alpha$ and ox-LDL co-treatment. After 30 min preincubation with or without anti-LOX-1 antibody $(10 \mu \mathrm{g} / \mathrm{ml})$, chondrocytes were co-treated with TNF- $\alpha(50 \mathrm{ng} / \mathrm{ml})$ and ox-LDL $(20 \mu \mathrm{g} / \mathrm{ml})$ for $24 \mathrm{~h}$, and LC3 level and pattern was analyzed by (A) western blotting and (B) confocal microscopy, respectively. (A) Increased LC3 II was found by western blotting in TNF- $\alpha$ and ox-LDL co-treated chondrocytes and this effect could be blocked by Lox-1 antibody pretreatment. (B) Enhanced LC3 pattern was found in TNF- $\alpha$ and ox-LDL co-treated chondrocytes and this effect could be blocked by Lox-1 antibody pretreatment. ${ }^{*} \mathrm{P}<0.05$ compared to control. ox-LDL, oxidized low density lipoprotein; Lox-1, lectin-like ox-LDL receptor-1; LC3, microtubule-associated proteins 1A/1B light chain 3B.

oxLDL, into joints. Furthermore, ox-LDL has suggested to play an important role in the pathogenesis of some ageing related disorders (eg. atherosclerosis) (18-20). In addition, both hypercholesterolemia and hypertension was identified as the risk factor for OA $(9,10)$. Taken together, these evidences suggested that ox-LDL may be involved in the OA. Therefore, we first collected the SF to perform the quantitative analysis of ox-LDL and significantly elevated ox-LDL was found in OA patients compared to normal controls.

LOX-1, firstly cloned from cultured bovine aortic endothelial cells, is identified as the receptor of ox-LDL (21). Previous studies have shown that the expression of LOX-1 on non-phagocytes, 
A

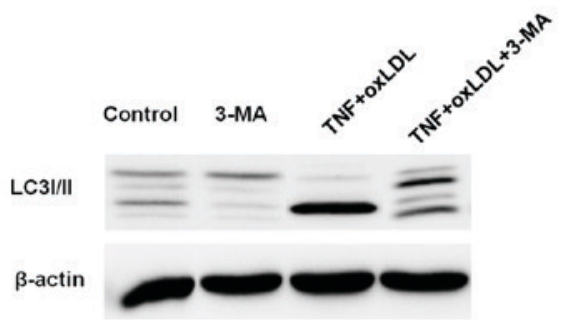

C

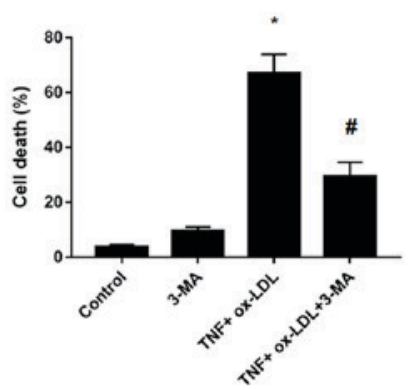

E

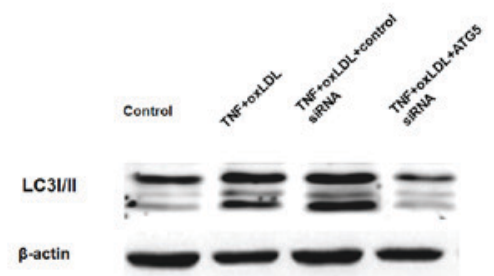

G

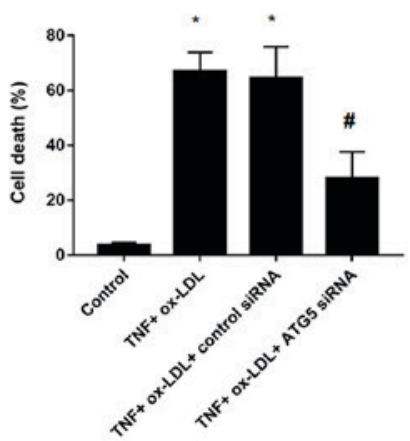

B

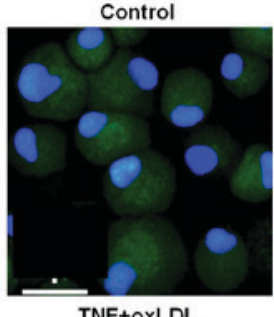

TNF+oxLDL

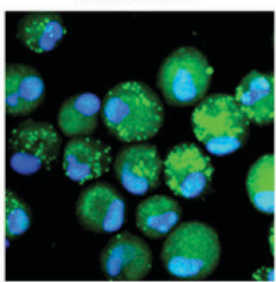

D

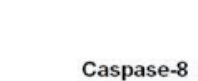

Cleaved caspase-8

Caspase-3

Cleaved caspase- 3

$\beta$-actin
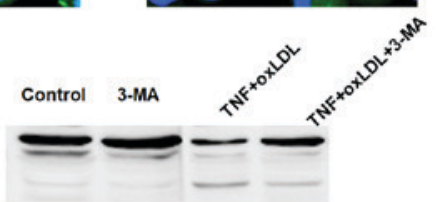

TNF+oxLDL+3-MA
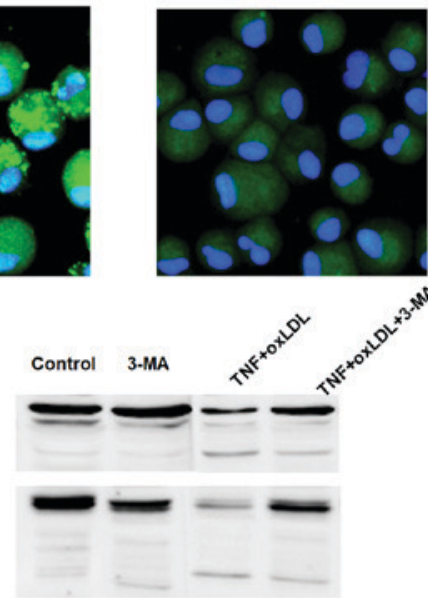

$\mathbf{F}$

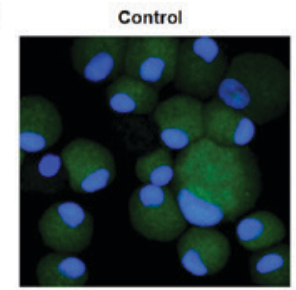

TNF+oxLDL+control siRNA
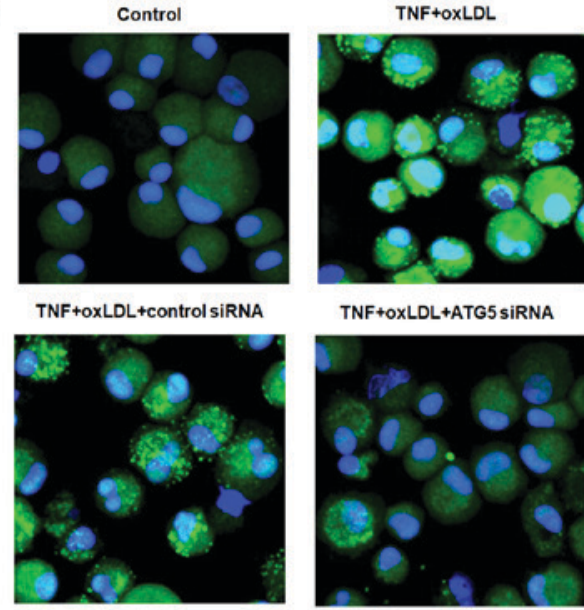

TNF+OXLDL+ATG5 SIRNA

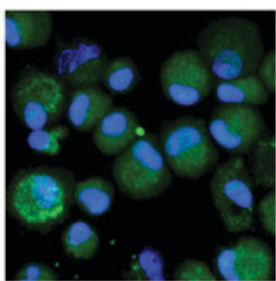

H

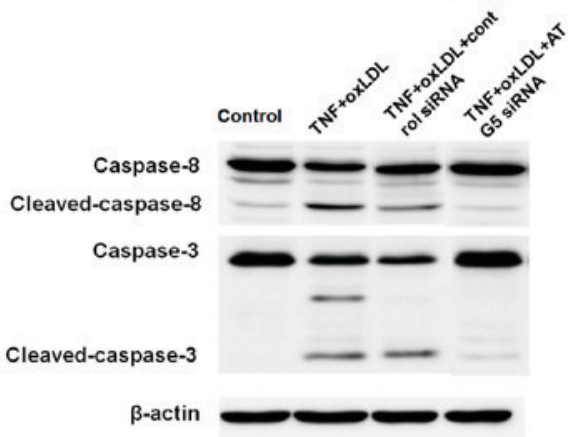

Figure 4. Autophagy inhibition by 3-MA or Atg-5 siRNA could reverse the effects mediated by TNF- $\alpha$ and ox-LDL co-treatment on chondrocytes. (A) Western blot analysis of the expression of LC3I/II. (B) LC3 pattern analysis by confocal microscopy. (C) Cell death analysis. (D) Western blot analysis of apoptosis related protein cleaved caspase-3 and caspase-8. 3-MA (5 mM) treatment could reverse the LC3II enhancement, punctuate LC3 pattern, increased cell death and cleaved caspase- 3 and caspase- 8 mediated TNF- $\alpha$ and ox-LDL co-treatment in chondrocytes. (E) Western blot analysis of the expression of LC3I/II. (F) LC3 pattern analysis by confocal microscopy. (G) Cell death analysis. (H) Western blot analysis of apoptosis related protein cleaved caspase-3 and caspase-8. Atg-5 siRNA treatment could reverse the LC3II enhancement, punctuate LC3 pattern, increased cell death and cleaved caspase-3 and caspase-8 mediated TNF- $\alpha$ and ox-LDL co-treatment in chondrocytes. ${ }^{*} \mathrm{P}<0.05$ compared to control, ${ }^{\prime \prime} \mathrm{P}<0.05$ compared to TNF- $\alpha+$ ox-LDL group. ox-LDL, oxidized low density lipoprotein; Lox-1, lectin-like ox-LDL receptor-1; si, small interfering; TNF- $\alpha$, tumor necrosis factor $\alpha$; LC3, microtubule-associated proteins 1A/1B light chain 3B; 3-MA, 3-methyladenine autophagy inhibitor; Atg-5, autophagy protein 5. 
such as vascular endothelial cells, smooth muscle cells, platelets and cardiomyocytes $(22,23)$, and inducible expression of LOX-1 could be found during the inflammation. Notably, it has been reported that expression of LOX and association of ox-LDL was found in chondrocytes of a rat model of arthritis (24). Moreover, treatment of these arthritis rats with anti-LOX-1 monoclonal antibody could suppress articular cartilage degeneration. In vitro chondrocytes model showed that enhanced LOX-1 expression could be found by treatment with ox-LDL and pro-inflammatory cytokine (eg.interleukin-1 $\beta$ ) (25). Here, we examined the expression of LOX-1 in cartilage tissue and our results showed that increased level of LOX-1 in cartilage tissue from OA patients compared to normal controls.

Two mechanisms are proposed to be involved in the TNF- $\alpha$ mediated chondrocyte apoptosis, including direct apoptosis induction and indirect apoptosis priming by Fas ligand presentation $(26,27)$. The proto-oncogenes of $\mathrm{Bcl}-2 / \mathrm{Bax}$ family are involved in the cellular signaling pathway of TNF- $\alpha$ mediated chondrocyte apoptosis, and activation of effector caspases (such as caspase-3 and caspase-8) are proposed as the downstream signaling events (28). We here found that ox-LDL could enhance the TNF- $\alpha$ mediated chondrocyte apoptosis as evidenced by increased level of cleaved caspases. Here, our found that cell death under the treatment of TNF- $\alpha$ is not significant higher than the control (Fig. 2A) and this result was consistent with several previous studies (29-32). However, the further investigate might be needed to prove the exact role of TNF- $\alpha$ on chondrocyte biology. Autophagy is a considered as the catabolic pathways for intracellular macromolecules degradation. At the beginning of autophagy, autophagosome was formed by sequestration of cytoplasmic organelles in a membrane vacuole. Then, fusion of the autophagosomes with lysosomes could result in degradation and recycling of the cellular materials. Recent studies have shown that increased autophagic activity could induce cell death $(33,34)$. According to previous studies, autophagy is an important cell survival mechanism under various forms of stress (35). Autophagy serves not only to regulate the final stages of the chondrocyte lifecycle, but also the rate at which chondrocytes enter the maturation process (36). Autophagy in normal adult articular cartilage is an important mechanism for cellular homeostasis (16). Catabolic and nutritional stresses could also increase autophagy in OA, and during the initial degenerative phase at least, autophagy is increased in OA chondrocytes and cartilage, with increased level of autophagy related molecules, including LC3 and Beclin-1 in OA chondrocytes (37). Here, we used TNF to induce inflammation to mimic the OA chondrocytes. Moreover, ox-LDL was shown to induce apoptosis in multiple cells (such as endothelial cells (38) and macrophages) (39) and we observed increased level of ox-LDL in OA patients, therefore, we add ox-LDL to the OA chondrocyte model and examined its effects. Increased LC3 represents the increased autophagy level, while increased caspase- 3 and caspase- 8 represents the executioner caspase and initiator caspase, respectively, during the cell apoptosis. Our results was consistent with the conclusion that both apoptotic as well as non-apoptotic mechanisms were involved in the cell death affected by OA, which were found by previous studies (16,40-42). According to previous description (40-42), both apoptotic as well as non-apoptotic mechanisms were involved in the cell death affected by OA and they also concluded that demonstrated that cell death of chondrocytes within OA undergoes changes different from the classical apoptosis and they considered that this type of death is a combination between the classical apoptosis and autophagy. Our results here supported these descriptions. Moreover, although the role of autophagy in cell death has been elucidated in multiple experimental and physiological system, controversial are existed on the positive or negative role of autophagy on cell death due to both cytoprotective and cell death functions are implicated during autophagy process (43-45). The results here suggested that autophagy inhibition could facilitate the chondrocytes survival during the challenge of TNF- $\alpha$ and ox-LDL. Here, we did not examine the effects of TNF- $\alpha$ inhibitors on change of LOX-1 expression level because we are unable to obtain the monoclonal antibodies for TNF-alpha inhibitor (46), but these examinations could be the potential future work.

In conclusion, we demonstrated here that ox-LDL could interaction with LOX-1 on chondrocyte and promote TNF- $\alpha$ mediated chondrocyte death via autophagy related mechanisms.

\section{Acknowledgements}

The present study was funded by National Nature Science Foundation of China to Yaozeng Xu (81472077 and 81672238).

\section{References}

1. Palazzo C, Nguyen C, Lefevre-Colau MM, Rannou F and Poiraudeau S: Risk factors and burden of osteoarthritis. Ann Phys Rehabil Med 59: 134-138, 2016.

2. Prieto-Alhambra D, Judge A, Javaid MK, Cooper C, Diez-Perez A and Arden NK: Incidence and risk factors for clinically diagnosed knee, hip and hand osteoarthritis: Influences of age, gender and osteoarthritis affecting other joints. Ann Rheum Dis 73: 1659-1664, 2014.

3. Lohmander LS and Roos EM: Clinical update: Treating osteoarthritis. Lancet 370: 2082-2084, 2007.

4. Loeser RF, Goldring SR, Scanzello CR and Goldring MB: Osteoarthritis: A disease of the joint as an organ. Arthritis Rheum 64: 1697-1707, 2012.

5. Zhang M, Mani SB, He Y, Hall AM, Xu L, Li Y, Zurakowski D, Jay GD and Warman ML: Induced superficial chondrocyte death reduces catabolic cartilage damage in murine posttraumatic osteoarthritis. J Clin Invest 126: 2893-2902, 2016.

6. Zhou Q, Sun Y, Zhang P and Zheng J: Simultaneously blocking necrosis and apoptosis to protect TMJ chondrocytes from TNF-alpha induced death: A preliminary study. Int J Clin Experiment Med 9: 2202-2210, 2016.

7. Jang KW, Buckwalter JA and Martin JA: Inhibition of cell-matrix adhesions prevents cartilage chondrocyte death following impact injury. J Orthop Res 32: 448-454, 2014.

8. Intekhab-Alam NY, White OB, Getting SJ, Petsa A, Knight RA, Chowdrey HS, Townsend PA, Lawrence KM and Locke IC: Urocortin protects chondrocytes from NO-induced apoptosis: A future therapy for osteoarthritis? Cell Death Dis 4: e717, 2013.

9. Niu J, Clancy M, Aliabadi P, Vasan R and Felson DT: Metabolic syndrome, its components, and knee osteoarthritis: The framingham Osteoarthritis study. Arthritis Rheumatol 69: 1194-1203, 2017.

10. Haugen IK, Ramachandran VS, Misra D, Neogi T, Niu J, Yang T, Zhang Y and Felson DT: Hand osteoarthritis in relation to mortality and incidence of cardiovascular disease: Data from the Framingham Heart Study. Ann Rheum Dis 74: 74-81, 2015.

11. Monira Hussain S, Wang Y, Cicuttini FM, Simpson JA, Giles GG, Graves S and Wluka AE: Incidence of total knee and hip replacement for osteoarthritis in relation to the metabolic syndrome and its components: A prospective cohort study. Semin Arthritis Rheum 43: 429-436, 2014. 
12. Bellamy N, Buchanan WW, Goldsmith $\mathrm{CH}$, Campbell J and Stitt LW: Validation study of WOMAC: A health status instrument for measuring clinically important patient relevant outcomes to antirheumatic drug therapy in patients with osteoarthritis of the hip or knee. J Rheumatol 15: 1833-1840, 1988.

13. Roorda LD, Jones CA, Waltz M, Lankhorst GJ, Bouter LM, van der Eijken JW, Willems WJ, Heyligers IC, Voaklander DC, Kelly KD and Suarez-Almazor ME: Satisfactory cross cultural equivalence of the Dutch WOMAC in patients with hip osteoarthritis waiting for arthroplasty. Ann Rheum Dis 63: 36-42, 2004

14. Ji Y, Strawn TL, Grunz EA, Stevenson MJ, Lohman AW, Lawrence DA and Fay WP: Multifaceted role of plasminogen activator inhibitor-1 in regulating early remodeling of vein bypass grafts. Arterioscler Thromb Vasc Biol 31: 1781-1787, 2011.

15. Goldring MB and Otero M: Inflammation in osteoarthritis. Curr Opin Rheumatol 23: 471-478, 2011.

16. Almonte-Becerril M, Navarro-Garcia F, Gonzalez-Robles A, Vega-Lopez MA, Lavalle C and Kouri JB: Cell death of chondrocytes is a combination between apoptosis and autophagy during the pathogenesis of Osteoarthritis within an experimental model. Apoptosis 15: 631-638, 2010.

17. Balci B: The modification of serum lipids after acute coronary syndrome and importance in clinical practice. Curr Cardiol Rev 7: 272-276, 2011.

18. Libby $\mathrm{P}$ and Hansson GK: Inflammation and immunity in diseases of the arterial tree: Players and layers. Circ Res 116 307-311, 2015 .

19. Perrins CJ and Bobryshev YV: Current advances in understanding of immunopathology of atherosclerosis. Virchows Archiv 458: 117-123, 2011.

20. Twardowski L, Cheng F, Michaelsen J, Winter S, Hofmann U, Schaeffeler E, Müller S, Sonnenberg M, Steuer K, Ott G, et al: Enzymatically modified low-density lipoprotein is present in all stages of aortic valve sclerosis: Implications for pathogenesis of the disease. J Am Heart Assoc 4: e002156, 2015.

21. Sawamura T, Kume N, Aoyama T, Moriwaki H, Hoshikawa H, Aiba Y, Tanaka T, Miwa S, Katsura Y, Kita T and Masaki T: An endothelial receptor for oxidized low-density lipoprotein. Nature 386: 73-77, 1997.

22. Xu S, Ogura S, Chen J, Little PJ, Moss J and Liu P: LOX-1 in atherosclerosis: Biological functions and pharmacological modifiers. Cell Mol Life Sci 70: 2859-2872, 2013.

23. Misaka T, Suzuki S, Sakamoto N, Yamaki T, Sugimoto K, Kunii H, Nakazato K, Saitoh S, Sawamura T, Ishibashi T and Takeishi Y: Significance of soluble lectin-like oxidized LDL receptor-1 levels in systemic and coronary circulation in acute coronary syndrome. Biomed Res Int 2014: 649185, 2014.

24. Nakagawa T, Akagi M, Hoshikawa H, Chen M, Yasuda T, Mukai S, Ohsawa K, Masaki T, Nakamura T and Sawamura T: Lectin-like oxidized low-density lipoprotein receptor 1 mediates leukocyte infiltration and articular cartilage destruction in rat zymosan-induced arthritis. Arthritis Rheum 46: 2486-2494, 2002

25. Nishimura S, Akagi M, Yoshida K. Hayakawa S, Sawamura T, Munakata $\mathrm{H}$ and Hamanishi C: Oxidized low-density lipoprotein (ox-LDL) binding to lectin-like ox-LDL receptor-1 (LOX-1) in cultured bovine articular chondrocytes increases production of intracellular reactive oxygen species (ROS) resulting in the activation of NF-kappaB. Osteoarthritis Cartilage 12: 568-576, 2004

26. Yumoto K, Nifuji A, Rittling SR, Tsuchiya Y, Kon S, Uede T, Denhardt DT, Hemmi H, Notomi T, Hayata T, et al: Osteopontin deficiency suppresses tumor necrosis factor- $\alpha$-induced apoptosis in chondrocytes. Cartilage 3: 79-85, 2012.

27. Kim J, Xu M, Xo R, Mates A, Wilson GL, Pearsall AW IV and Grishko V: Mitochondrial DNA damage is involved in apoptosis caused by pro-inflammatory cytokines in human OA chondrocytes. Osteoarthritis Cartilage 18: 424-432, 2010.
28. Csaki C, Mobasheri A and Shakibaei M: Synergistic chondroprotective effects of curcumin and resveratrol in human articular chondrocytes: Inhibition of IL-1beta-induced NF-kappaB-mediated inflammation and apoptosis. Arthritis Res Ther 11: R165, 2009.

29. Caramés B, López-Armada MJ, Cillero-Pastor B, Lires-Dean M, Vaamonde C, Galdo F and Blanco FJ: Differential effects of tumor necrosis factor-alpha and interleukin-1beta on cell death in human articular chondrocytes. Osteoarthritis Cartilage 16: 715-722, 2008

30. López-Armada MJ, Caramés B, Lires-Deán M, Cillero-Pastor B, Ruiz-Romero C, Galdo F and Blanco FJ: Cytokines, tumor necrosis factor-alpha and interleukin-1beta, differentially regulate apoptosis in osteoarthritis cultured human chondrocytes. Osteoarthritis Cartilage 14: 660-669, 2006.

31. Lee SW, Song YS, Lee SY, Yoon YG, Lee SH, Park BS, Yun I, Choi H, Kim K, Chung WT and Yoo YH: Downregulation of protein kinase CK2 activity facilitates tumor necrosis factor- $\alpha$-mediated chondrocyte death through apoptosis and autophagy. PLoS One 6: e19163, 2011.

32. Jiang LB, Meng DH, Lee SM, Liu SH, Xu QT, Wang Y and Zhang J: Dihydroartemisinin inhibits catabolism in rat chondrocytes by activating autophagy via inhibition of the NF- $\kappa \mathrm{B}$ pathway. Sci Rep 6: 38979, 2016.

33. Wang K: Autophagy and apoptosis in liver injury. Cell Cycle 14: $1631-1642,2015$

34. Jia J, Yao W, Guan M, Dai W, Shahnazari M, Kar R, Bonewald L, Jiang JX and Lane NE: Glucocorticoid dose determines osteocyte cell fate. FASEB J 25: 3366-3376, 2011.

35. Mizushima N: Physiological functions of autophagy. Curr Top Microbiol Immunol 335: 71-84, 2009.

36. Shapiro IM, Layfield R, Lotz M, Settembre C and Whitehouse C: Boning up on autophagy: The role of autophagy in skeletal biology. Autophagy 10: 7-19, 2014

37. Sasaki H, Takayama K, Matsushita T, Ishida K, Kubo S, Matsumoto T, Fujita N, Oka S, Kurosaka M and Kuroda R: Autophagy modulates osteoarthritis-related gene expression in human chondrocytes. Arthritis Rheum 64: 1920-1928, 2012.

38. Hong D, Bai YP, Gao HC, Wang X, Li LF, Zhang GG and $\mathrm{Hu}$ CP: Ox-LDL induces endothelial cell apoptosis via the LOX-1-dependent endoplasmic reticulum stress pathway. Atherosclerosis 235: 310-317, 2014

39. Zheng H, Cui D, Quan X, Yang W, Li Y, Zhang L and Liu E: Lp-PLA2 silencing protects against ox-LDL-induced oxidative stress and cell apoptosis via Akt/mTOR signaling pathway in human THP1 macrophages. Biochem Biophys Res Commun 477: 1017-1023, 2016.

40. Del Carlo M Jr and Loeser RF: Cell death in osteoarthritis. Curr Rheumatol Rep 10: 37-42, 2008.

41. D'Lima D, Hermida J, Hashimoto S, Colwell C and Lotz M: Caspase inhibitors reduce severity of cartilage lesions in experimental osteoarthritis. Arthritis Rheum 54: 1814-1821, 2006.

42. Kuhn K, D'Lima DD, Hashimoto S and Lotz M: Cell death in cartilage. Osteoarthritis Cartilage 12: 1-16, 2004.

43. Mathew R and White E: Autophagy in tumorigenesis and energy metabolism: Friend by day, foe by night. Curr Opin Genet Dev 21: 113-119, 2011.

44. Bhutia SK, Mukhopadhyay S, Sinha N, Das DN, Panda PK, Patra SK, Maiti TK, Mandal M, Dent P, Wang XY, et al: Autophagy: Cancer's friend or foe? Adv Cancer Res 118: 61-95, 2013.

45. Marx J: Autophagy: Is it cancer's friend or foe? Science 312: 1160-1161, 2006

46. Lis K, Kuzawinska O and Bałkowiec-Iskra E: Tumor necrosis factor inhibitors-state of knowledge. Arch Med Sci 10: 1175-1185, 2014. 